\title{
К ПРОБЛЕМЕ РЕЧЕВОЙ ИЗБЫТОЧНОСТИ: СЛОВА-ПАРАЗИТЫ
}

\author{
Т. В. Федотова
}

Кубанский государственный аграрный университет имени И. Т. Трубилина

\section{ON THE PROBLEM OF SPEECH REDUNDANCY: WORD PARASITES}

\author{
T. V. Fedotova \\ I. T. Trubilin Cuban State Agrarian University
}

\begin{abstract}
Аннотация: в статье анализируются функиионально-семантические разновидности слов-паразитов в речи современной молодежи. Представлены результаты лингвистического анализа парентез, полученных экспериментальным методом (опрос, анкетирование) в аспекте их психолого-семантической наполненности. Поднимается вопрос об осознанной мотивации говорящего в процессе речевого акта с целью использования парентез. Новизна исследования видится в том, что выделены функиионально-семантические блоки, фиксирующие слова-паразиты с позиции интенций говорящего, а также включено описание их текстообразующих функиий. Актуальность исследования обусловлена возрастающей проблемой активизачии слов-паразитов в речи современной молодежс. Автор останавливается на понятии «парентеза» в значении «слова-паразиты» и точках зрения на проблему их функиионирования в различных речевых аспектах. Доказано, что слова-паразиты имеют определенную смысловую нагрузку и независимо от их неосознанного употребления выполняют конкретные функиии в речевом акте. Предлагается классификация слов-паразитов в функционально-психолого-семантическом аспекте. Выполнен обзор наиболее употребляемых слов-паразитов с указанием мотиваџионной составляющей, входящей в интениии говорящего.
\end{abstract}

Ключевые слова: речевая избыточность, речевой акт, высказывание, слова-паразиты, парентеза, функицонально-семантический, апеллятивный, фатический.

\begin{abstract}
: the article analyses the functional-semantic differences of word-parasites in the speech of modern youth. Results of linguistic analysis of parenthesis obtained by experimental method (survey, questionnaire) in aspect of their psycho-semantic filling are presented. The question of the conscious motivation of a speaker in the course of a speech act with a view to using parenthesis is discussed. The novelty of the study is seen in the fact that functional-semantic blocks are identified, fixing word-parasites from the position of intentions of the speaker, as well as a description of their text-forming functions is included. The relevance of research was due to the increasing problem of activation of word parasites in speech of young people. The author focuses on the concept of "parenthesis" meaning of "word parasites" and the problem of their functioning in various speech aspects. Parasite words have been proven to have a certain sense load and, regardless of their unconscious use, perform specific functions in a re-act. Classification of word parasites in functional-psycho-semantic aspects is proposed. The most used parasite words were reviewed with an indication of the motivational component included in the intentions of the speaker.
\end{abstract}

Key words: speech redundancy, speech act, statement, filler words, parenthesis, functional and semantic, appellative, phatic.

Введение: к проблеме экологизации языка

Эволюция в любой сфере научного знания подразумевает естественный процесс развития, сопровождающийся изменением уровней организации системы как в сторону прогресса, так и в сторону регресса.

В лингвистических исследованиях последнего времени остро встает вопрос о проблеме проникно-

(C) Федотова Т. В., 2020

Контент доступен под лицензией Creative Commons Attribution 4.0 License.

The content is available under Creative Commons Attribution 4.0 License. 
вения иностранных слов в русский язык, которые, по мнению большинства ученых, разрушают устои русской речи [1]. Часто в адрес заимствований звучит такое определение, как «загрязненность» современного русского языка. Безусловно, данный факт языка имеет негативные последствия для народа, стремящегося сохранить свою культуру, духовные ценности, так как язык всегда являлся средством национальной идентичности. Так, по мнению Е. П. Франко, «для высокообразованного человека, живущего в век величайших открытий, на первом месте должно быть глубокое знание родного языка, виртуозное владение литературным слогом. Все это и включает в себя “экологизация” языка» [2, с. 27].

Вне всякого сомнения, иностранные заимствования отрицательно влияют на сохранение русской культуры в силу того, что зачастую заимствуются слова, имеющие не менее точные русские эквиваленты: конверсия (преобразование), стагнация (застой), консенсус (соглашение), презентация (представление) и др. [3, с. 110]. Данный процесс отражает одну из черт языкового вкуса современного человека - создание «книжности», изощренности речи. С точки зрения современного человека, подобные слова делают речь более привлекательной. Другое дело, если эти слова присутствуют в словарном запасе говорящего.

Однако если подойти к вопросу с позиции большинства представителей молодого поколения, то можно заметить, что вопрос экологии языка гораздо серьезнее не в плане распространенного процесса заимствований, а в плане либерализации, демократизации языка. Норма становится менее обязательной. Молодежь все больше привлекают разного рода «загрязнители» литературного языка: жаргон, просторечие, слова-паразиты. Как справедливо отмечает В. Г. Костомаров: «Пример берется с американской масс-культуры, давно уже освободившейся от эстетико-нравственных ограничений...» [3, с. 79].

Речевая культура современного общества стремительно падает, несмотря на постоянное обогащение речи заимствованной лексикой. Особенно остро это явление просматривается в речи молодежи, где «обнищание» словарного запаса заменяется (как правило, в устной речи) использованием жаргонизмов, просторечия и слов-паразитов. Если жаргонизмы и просторечия - достаточно осознанные вкрапления в устную речь говорящего, то слова-паразиты, по мнению многих исследователей, зачастую неосознанные употребления для заполнения речевых лакун, связанных с небольшим словарным запасом.

В то же время анализ употребления данных слов свидетельствует, что их включение в устную речь не всегда показатель бедного лексикона говорящего. Справедливо, на наш взгляд, утверждение М. А. Кронгауза, что в языке ведь вообще нет ничего лишнего.
За каждым словом стоит некая идея, которая в определенный речевой момент может быть востребованной, часто воспроизводимой, и лишь потом, когда возникает устойчивая привычка к слову, оно становится тем самым паразитом, от которого почти невозможно избавиться [4, с. 74]. Однако в любом случае говорящий, используя подобные слова, преследует определенную цель: оттянуть время для обдумывания следующей фразы, выразить эмоции, подчеркнуть логику изложения и т. д.

Соответственно, цель статьи - проанализировать все возможные мотивы и смыслы функционирования слов-паразитов в речи молодежи.

\section{Слова-паразиты с позиции коммуникативных установок}

В лингвистике присутствует понятие парентезы, которая обозначает слово, словосочетание или предложение, введенное в контекст с целью усиления, выразительности. Чаще всего к ним относят вводные и вставные конструкции. По мнению О. В. Мюллеровой [5, с. 252], парентетические внесения имеют разнообразные положительные функции и даже в случаях неправильного употребления в виде слов-паразитов могут иметь не деструктивный, а наоборот, продуктивный характер.

С позиции системно-функционального подхода парентезы могут выполнять двоякую функцию: с одной стороны, осложнять структуру монопредикативного или полипредикативного предложения путем включения в его состав обособленных слов или синтаксических конструкций, а с другой - способствовать лаконичному изложению информации [6, с. 30].

В лингвистике словам-паразитам отведено значительное место в плане изучения их разноплановой направленности: функциональная наполненность (А. Д. Шмелев); ритмическая организация речи (Н. Н. Розанова); лингвоэкология и лингвокультурология (А. Д. Васильев, О. В. Трофимова), явление десемантизации (Т. И. Антонова, А. Н. Иванова).

$\mathrm{B}$ речи молодежи парентетические включения функционируют в виде слов-паразитов, которые выполняют различные функции. В лингвистике утвердилось мнение, что употребление таких слов - неосознанное заполнение речевых лакун в потоке речи, связанных с невысоким уровнем культуры речи, бедным словарным запасом, без какой-либо коммуникативной цели [5]. Данное мнение напрямую связано с проблемой «чистоты» русского языка, которая в последнее время становится одной из центральных, связанных с экологией русского языка [7, с. 12].

В то же время анализ подобной лексики позволяет высказать предположения иного рода, где на первый план выходит не отсутствие речевой культуры, 
а более глубинные, психологические факторы, не всегда зависящие от лингвистических факторов.

При более тщательном анализе включаемых в речь лексем можно констатировать не только их функциональное разнообразие, но и зачастую осознанный характер включения, основанный как на привлечении внимания собеседника, как ответ-реакция на созданную речевую провокацию и т. п.

В качестве социального объекта исследования выступили носители русского языка, а именно студенты-первокурсники Кубанского государственного аграрного университета имени И. Т. Трубилина. Лингвистическим объектом послужили слова-паразиты, собранные методом наблюдения за живой речью, а также анкетированием. Основными задачами исследования выступили следующие:

- анализ мотивационной стороны парентетических включений с учетом частотности использования слов-паразитов в речи студентов;

- выявление и создание психолого-ситуационных блоков, где эксплицируются интенции говорящих в аспекте использования исследуемых лексем.

Говоря о мотивационной стороне в привлечении слов-паразитов, следует заметить, что их значительная часть не имеет грамматической связи с остальными компонентами высказывания [6, с. 33]. В то же время использование каждой парентетической лексемы, словосочетания не всегда является неосознанным процессом. Проанализировав эмпирический материал, можно выделить мотивационные блоки, которые эксплицируют интенции говорящего с позиции тактической задачи включения данных слов в процесс коммуникации.

Всего, на наш взгляд, можно выделить шесть мотивационных блоков, где в той или иной мере отражаются коммуникативные установки говорящего для включения исследуемых слов:

1) текстообразующий (коннективный) блок;

2) блок хезитации;

3) блок экономии языковых средств;

4) эмоциональный блок;

5) психологический блок;

6) фатический блок.

1. Тексторообразующий блок включает слова, которые выполняют определенную роль в членении текста, в реализации риторической категории диалогизации [6, с. 33]. Употребление отдельных парентез связано как с возрастом коммуниканта, так и с его словарным запасом. Так, студенты старших курсов в качестве связующего звена употребляют выражения типа дело в том, что в качестве зачина при ответе на вопрос. Причем использование такого выражения позволяет отвечающему немного оттянуть время для ответа, подумать для вербальной реализации какой-либо мысли. Аналогичную функцию выполняет употребление слова-паразита вот в конце изложения определенной мысли. Данное слово дает возможность говорящего сконцентрироваться на изложении следующей мысли. Такое поведение наблюдается у студентов при ответе на семинарских занятиях, зачастую его используют и при ораторских выступлениях, где необходимо в течение короткого времени доказать какую-либо точку зрения.

Не меньшей популярностью пользуется слово соответственно. Слово часто употребляется преподавателями на лекциях, и студенты начинают активно включать его в свою речь. Функция данной лексемы очевидна - коннективность для создания видимости логики при изложении материала.

К текстообразующим парентезам можно отнести и устойчивые выражения так сказать и как говорится. В качестве вводных сочетаний данные выражения имеют смысл: как говорится - «как говорят, как принято говорить»; так сказать служит извинительной пометой при нарушении речевого стандарта, когда употребляемое слово или выражение имеет не совсем привычный характер. Таким образом, можно сказать, что с помощью так сказать и в предложение вносится оценка составляющих его средств в аспекте их стандартности [8, с. 125]. Если же данные выражения не включают названные смыслы, то они зачастую выступают в качестве выражений, создающих логическую паузу и, как многие считают, делают речь более замысловатой и многозначной.

Аналогичную функцию выполняют и слова и выражения типа собственно говоря, допустим, иначе говоря и т. п.

2. Блок хезитации включает слова, употребляемые говорящим в период вербальной паузы. Хезитация (от англ. hesitation - колебание) - речевое колебание, связанное со спонтанностью речи, при котором возникает проблема выбора речевых единиц и планирования предложения в целом. Как правило, употребление слов-паразитов - это неосознанный процесс, связанный с речевыми привычками говорящего. Так, О. А. Александрова выделяет фонетико-фонологические паузы или вокализации (м-м, хм, гм, а-а, э-э), лексико-семантические паузы (ну, такой, этот, самый, так, значит, в общем, это самое) и метатекстовые включения (короче говоря, по правде говоря, что касается меня, в принципе, знаете, знаешь, понимаете, в принципе, честно говоря, кстати) [9].

Употребление подобных слов не всегда мотивируется торопливостью речи, небольшим словарным запасом. Иногда отдельные слова и выражения функционируют в речи в качестве определенной модной тенденции. Например, у молодежи наиболее часто употребляемым является выражение в принциипе, которое, если оно употребляется осознанно, сигнализирует, что человек согласен на что-то, но еще не до 
конца уверен. Чаще данное выражение употребляется как «модная» тенденция.

3. Экономия языковых средств происходит в результате спонтанности речевого акта, когда коммуникант не имеет времени для обдумывания предполагаемого высказывания, стремясь одновременно достичь понимания реципиента. С точки зрения говорящего, использование определенных лексем способствует достижению коммуникативной цели. Иначе говоря, в целях языковой экономии наблюдается не сокращение или свертывание языковых единиц, а наоборот, насыщение речи парентезами, более емкими языковыми знаками, с точки зрения говорящего. Лексические вставки в такой ситуации дополняют высказывание в эмоционально-оценочном аспекте, «усиливают основную, предметно-логическую» сторону [6, с. 33].

По мнению В. В. Антоновой, вводные конструкции, имеющие статус средства языковой экономии, «не только вносят в содержание предложения те или иные значения субъективной модальности, но выполняют функции союзов, становятся структурно необходимыми элементами» [6, с. 34]. Кроме того, такие парентетические вставки являются эффективным текстообразующим средством, которое направлено на облегчение процесса построения высказывания.

В качестве примеров, имеющих отношение к экономии языковых средств, с точки зрения говорящего, можно рассматривать короче (семантика краткости, желание свернуть длинную мысль в короткий тезис; отказ от детализованного представления ситуации), в общем (желание подытожить сказанное и перейти к следующему вопросу), все такое (нежелание перечислять какие-либо аналогичные факты, указав на их идентичность данной вставкой).

Таким образом, фактор экономии языковых средств работает параллельно с фактором логичности, дополняет его, тем самым выполняя текстообразующую функцию.

4. Эмоциональный блок - группа слов, фраз, создающих эмоционально-экспрессивную тональность речи. Употребление участниками коммуникации парентез в данной ситуации направлено на создание обоюдного состояния психоэмоционального комфорта [10, с. 107].

Эмоциональные включения, как правило, происходят либо в процессе речевого потока, либо выступают как оценка ситуации в целом. Многие из таких парентез являются цензурными аналогами обсценных слов: блин, ё-моё, пипеи, капец, ёпрст, жесть, трэи, ёикин кот, ёперный театр, твою дивизию, в цзвет, ёксель-моксель и т. п.

Наиболее распространенным в данной речевой ситуации выступает слово блин. По мнению многих лингвистов, эта лексема как заменитель обсценной лексики самая употребляемая [11, с. 63]. Эмоции, выражаемые этим словом, разнообразны с психологической точки зрения: радость, удивление, восторг, досада, негодование, злость, разочарование и т. п.

Функционирование данного и аналогичных ему слов свидетельствует не только о снижении уровня речевой культуры, но и, по мнению Г. М. Литвиновой, «об усилении речевой и поведенческой агрессии в нашем обществе» [11, с. 63]. Как отмечает В. Г. Костомаров, «общественный вкус нынешнего времени, несомненно, диктует демократизацию речи... за счет заимствований из вне- и нелитературных сфер общественного языка» [3, с. 78], привлечения в литературный язык «элементов некодифицированной речи: единиц просторечия, территориальных диалектов, жаргонов, так называемой городской речи» [12].

Нельзя согласиться с мнением Г. Грайса, что эвфемизмы помогают избежать коммуникативный дискомфорт [13, с. 223]. Безусловно, употребление обсценной лексики и ее заменителей различается с точки зрения степени табуированности. Однако мотивационный аспект их включения в речевой акт практически идентичен. Остается лишь осознавать тот факт, что данные слова прочно вошли в речь всех слоев населения, «даже тех, кто претендует на речевую элитарность» [11, с. 65].

5. Психологический блок включает парентетическую лексику, которая употребляется говорящим с позиции определенной психологической установки. Это могут быть сомнения, неуверенность, нежелание нести ответственность за сказанное. Это самая распространенная группа слов-паразитов, которая свидетельствует в большей степени о том, что носители русского языка в большинстве своем - люди неуверенные, сомневающиеся. Обладатели этих признаков, если говорить о молодом поколении, употребляя парентетическую лексику, тем самым рефлекторно пытаются скрыть бедность словарного запаса, завуалировать свое нежелание отвечать за сказанное.

Самым распространенным представителем лексики данной группы выступает как был. С точки зрения норм литературного языка, данное сочетание употребляется при выражении предположительности, условности высказывания, соответствуя по значению словам будто, будто бы. Однако в последнее время как бы стало самым распространенным словом-паразитом во всех слоях общества.

Многочисленное количество исследований по выявлению мотивов употребления этого сочетания в речи свидетельствует о все более растущем, просто стихийном увлечении этим речевым «сорняком» не только в речи молодого поколения, но и в речи людей всех возрастов. Безусловно, полная бесконтрольность за речевым актом присуща людям низкого уровня образования: «Я как бы с ним встречалась, и он меня 
как бы бросил» (Ток-шоу «Мужское и женское»). В некоторой степени подобные фразы характеризуют психологическое состояние говорящего, даже в некоторой степени его социальный статус. По мнению М. Кронгауза, «фактически оно (выражение) означает, что говорящий отказывается делать резкие и окончательные высказывания о мире, а каждый раз заявляет о своей неуверенности, об отсутствии у него права делать такие утверждения, и в том числе о его невысоком статусе, в частности по отношению к собеседнику» [4, с. 76].

Специалисты пришли к выводу, что употребление $\kappa a \kappa ~ б b l$ в этих слоях общества - это либо неопределенность, либо нежелание нести ответственность за сказанное. У молодежи, по результатам анкетирования, парентеза как бы употребляется в ситуации неточности знаний, слабой подготовленности, неуверенности в своих знаниях. Похожую функцию, а именно использование парентезы вследствие нежелания нести ответственность за сказанное, выполняет лексема просто. Предложения со словом «просто» характерны для людей, вообще боящихся ответственности. Они будут твердить, что это обстоятельства, а не они виноваты в происходящем.

Следом за как бы уверенно шествует лексема muna. Данное слово может относиться к нескольким блокам, однако основной мотив его употребления выражение неуверенности в излагаемой фразе, сложность в выборе слова и т. п., что может быть аналогом вроде бы, вроде того. В другой своей функции типа выступает в качестве уточнения, пояснения. По мнению М. А. Кронгауза, слово типа стало всего лишь стилистическим (поначалу «бандитским», а потом хоть вульгарным, но общенародным) вариантом незадолго до этого распространившегося обычного слова-паразита как бы. Слова, подобные типа и как $\sigma b l$, восходят к совершенно нормальным русским словам, которые вдруг начинают употребляться чаще и в совершенно неуместных контекстах и ситуациях. В литературном языке эти два слова связаны с идеей сходства, подобия (но не совпадения), однако в «паразитическом» употреблении они от данной функции отходят [4, с. 75$]$.

Менее употребляемое, но любимое молодым поколением слово походу также сигнализирует о неуверенности коммуниканта. Данную лексему целесообразно рассматривать в качестве синонима к вводному слову по-видимому, которое имеет ту же семантику. Можно предположить, что употребление лексемы походу свидетельствует о том, что высказанная говорящим мысль не совсем серьезна и часто носит несерьезный характер: Она, походу, вообще не хочет отвечать...

В противовес неуверенности активно используется выражение на самом деле, которое сигнализиру- ет о повышенной самоуверенности говорящего. Человек, часто употребляющий данную фразу, уверен, что только ему известна истина.

Таким образом, психологические парентезы можно рассматривать как одно из свойств интуиции носителя конкретного языка, а именно неосознанное влияние его психолингвистического механизма.

6. Фатический блок фиксирует слова, используемые в акте коммуникации с целью установления контакта с собеседником и, как правило, не несущие никакой смысловой нагрузки. Отметим наиболее распространенные с этой точки зрения парентетические включения.

Лексема нет используется с целью перебить собеседника, чтобы высказать свое мнение. Кроме того, употребление данного слова служит своеобразным сигналом завышенной уверенности говорящего в позиции, которую он собирается озвучить, т. е. наблюдается взаимодействие двух функций в процессе употребления данного слова.

Элементарными показателями привлечения внимания служат слова кстати и слушай. Кстати, в свою очередь, является сигналом того, что коммуникант намерен вклиниться в разговор, причем нередко со сменой темы предшествующего речевого акта. Аналогична функция и слова-паразита слушай, которое используется с целью как привлечения внимания, так и с интенцией сообщить нечто важное.

Слова вот, знаете, понимаете включаются говорящим в двух случаях: дать собеседнику время осмыслить сказанное и подготовиться к новой информации либо получить относительную поддержку (часто невербальную) в момент своего монолога. М. А. Кронгауз считает, что «эти вроде бы и паразиты в действительности очень нужны говорящему и выдают его особый психологический склад, потребность в постоянной коммуникативной поддержке и связи с собеседником» $[4$, с. 74$]$.

\section{Заключение}

Таким образом, исходя из перечисленных функционально-семантических разновидностей парентетических включений, можно констатировать, что они несут определенный смысл, некую идею, возможно, в процессе коммуникации и не всегда осознанные. Первоначально описанные слова употреблялись совершенно осознанно. С течением времени, ввиду частого употребления, такие слова приобретают «паразитический» характер, однако идейная составляющая никуда не уходит, она лишь проявляется не очень четко и не всегда осознанно - возникает устойчивая привычка к тому или иному слову.

Использование слов-паразитов в речи молодежи зависит не только от моды, от «узуса», но и от инди- 
видуальных предпочтений говорящего, а также от конкретных целей: привлечь внимание, завершить логическую цепочку, не нести ответственность за определенные высказывания, заполнить лексические лакуны своего словарного запаса и т. д.

Иначе говоря, слова-паразиты - своеобразные маркеры в языковом портрете говорящего, которые должны быть сигналом для самого коммуниканта в аспекте развития языковой рефлексии в процессе речевого акта. Безусловно, некоторые из перечисленных блоков с их составляющими имеют положительный характер и не обременяют в речевом аспекте реципиента, однако любое чрезмерное увлечение парентезами ведет к коммуникативному провалу и к отрицательной характеристике речевых возможностей коммуниканта со стороны реципиента.

\section{ЛИТЕРАТУРА}

1. Калинин А. В. Русская лексика. М., 2014. 232 с.

2. Франко Е. П., Франко М. В. Экология языка в современном обществе // Политическая лингвистика. 2019. № 5. C. 26-34.

3. Костомаров В. Г. Языковой вкус эпохи. Из наблюдений над речевой практикой масс-медиа. СПб. : Златоуст, 1999. 320 с.

4. Кронгауз М. А. Ключевые слова эпохи // Слово. ру : Балтийский акцент. 2010. № 1-2. С. 69-76.

5. Мюллерова О. В. Лики языка. М. : Наследие, 1998. C. 251-263.

6. Антонова В. В. О текстообразующем потенциале парентезы в современном русском языке // Русистика. 2012. № 2. С. 30-35.

7. Горбунова И. В. Социолингвистический эксперимент в образовательном пространстве : к проблеме использования слов-паразитов в русской разговорной речи // Бизнес-образование в экономике знаний. 2019. № 1 (12). С. 12-17.

8. Шмелева Т. В. «Так сказать» и «как говорится» // Служебные слова : сб. ст. Новосибирск, 1987. С. 125132.

9. Александрова О. А. Речекоммуникативный статус паузы колебания. Великий Новгород, 2004.

10. Курьянович A. В. Инвективные речевые жанры в пространстве современной межличностной коммуникации // Вестник ТГПУ. 2005. № 3. С. 106-112.

11. Литвинова Г. М. К проблеме употребления слов-паразитов в современном русском языке // Вестник Моск. ун-та. Серия 22. Теория перевода. 2012. № 2. C. $55-69$.

12. Бельчиков Ю. А. О роли СМИ в процессе демократизации русского литературного языка // Вестник электронных и печатных СМИ. 2011. № 13. С. 7.
13. Грайс Г. Логика и речевое общение // Новое в зарубежной лингвистике. М., 1985. Вып. 16. С. 5-24.

\section{REFERENCES}

1. Kalinin A. V. Russkaya leksika [Russian vocabulary]. Moscow, 2014.

2. Franko E. P. E`kologiya yazy`ka v sovremennom obshhestve [Ecology of language in modern society]. In: Politicheskaya lingvistika. 2019. No. 5. Pp. 26-34.

3. Kostomarov V. G. Jazy kovoj vkus e poxi. Iz nablyudenij nad rechevoj praktikoj mass-media [The language taste of the epoch. Some observations on speech practices of mass media]. Sankt-Peterburg: Zlatoust, 1999.

4. Krongauz M. A. Klyuchevy`e slova epokhi [Key words of the epoch]. In Slovo.ru: Baltijskij akcent. 2010. No. 1-2. Pp. 69-76.

5. Myullerova O. V. Liki yazy`ka [Faces of language]. M. : Nasledie, 1998. Pp. 251-263.

6. Antonova V. V. O tekstoobrazuyushhem potenciale parentezy` $\mathrm{v}$ sovremennom russkom yazy`ke [On the text-forming potential of the parenthesis in the modern Russian language]. In Rusistika. 2012. No. 2. Pp. 30-35.

7. Gorbunova I. V. Sociolingvisticheskij e`ksperiment v obrazovatel'nom prostranstve: k probleme ispol 'zovaniya slov-parazitov v russkoj razgovornoj rechi [Sociolinguistic experiment in education: on the problem of using words-parasites in Russian colloquial speech]. In Biznes-obrazovanie v ekonomike znanij. 2019. No. 1 (12). Pp. 12-17.

8. Shmeleva T. V. «Tak skazat"» $\mathrm{i}$ «kak govoritsya» ["So to say" and "as it is said". In Sluzhebnyje slova: Sbornik statej. Novosibirsk, 1987. Pp. 125-132.

9. Aleksandrova O. A. Rechekommunikativny j status pauzy kolebaniya [The status of hesitative pauses in speech and communication]. Velikij Novgorod, 2004.

10. Kur`yanovich A. V. Invektivny`e rechevy`e zhanry` v prostranstve sovremennoj mezhlichnostnoj kommunikacii [Invective speech genres in interpersonal communication]. In: Vestnik TGPU. 2005. No. 3. Pp. 106-112.

11. Litvinova G. M. K probleme upotrebleniya slov-parazitov v sovremennom russkom yazy`ke [On the problem of the "words-parasites usage]. In Vestnik Moskovskogo universiteta. Seriya 22. Teoriya perevoda. 2012. No. 2. Pp. 55-69.

12. Bel 'chikov Yu. A. O roli SMI v processe demokratizacii russkogo literaturnogo jazyka [On the role of mass media in the process of democratization of the Russian standard language]. In Vestnik elektronnykh i pechatnykh SMI. 2011. No. 13. P. 7.

13. Grice G. Logika i rechevoe obshhenie. [Logic and communication]. In: Novoe v zaru-bezhnoj lingvistike. Moscow, 1985. Vol. 16. Pp. 5-24. 
Кубанский государственный аграрньій университет имени И. Т. Трубилина

Федотова Т. В., профессор кафедры русского языка и речевой коммуникации

E-mail:Fedotova66@mail.ru

Поступила в редакциюю 10 апреля 2020 г.

Принята к публикачии 15 июня 20202.

\section{Для цитирования:}

Федотова Т. В. К проблеме речевой избыточности: слова-паразиты // Вестник Воронежского государственного университета. Серия: Лингвистика и межкультурная коммуникация. 2020. № 3. C. 47-53. DOI: https://doi. org/10.17308/lic.2020.3/2932
I. T. Trubilin Kuban State Agricultural University

Fedotova T. V., Professor of the Russian Language and Speech Communication Department

E-mail:Fedotova66@mail.ru

Received: 10 April 2020

Accepted: 15 June 2020

\section{For citation:}

Fedotova T. $V$. On the problem of speech redundancy: word parasites. Proceedings of Voronezh State University. Series: Linguistics and Intercultural Communication. 2020. No. 3. Pp. 47-53. DOI: https://doi.org/10.17308/lic. $2020.3 / 2932$ 